Article

\title{
Preliminary Numerical Analysis of a Novel Retaining System in Dry Sandy Soil and Its First Application to a Deep Excavation in Wuhan (China)
}

\author{
Yapeng Zhang ${ }^{1,2}$, Congxin Chen ${ }^{1}$, Meiqing Lei ${ }^{1}$, Yun Zheng ${ }^{1, *}$, Haina Zhang ${ }^{1,2}$ and \\ Yong Shao ${ }^{1,2}$ \\ 1 State Key Laboratory of Geomechanics and Geotechnical Engineering, Institute of Rock and Soil Mechanics, \\ Chinese Academy of Sciences, Wuhan 430071, Hubei, China; zhangyapeng17@mails.ucas.edu.cn (Y.Z.); \\ cxchen@whrsm.ac.cn (C.C.); W1324@163.com (M.L.); zhanghaina15@mails.ucas.ac.cn (H.Z.); \\ Shyong@csu.edu.cn (Y.S.) \\ 2 University of Chinese Academy of Sciences, Beijing 100049, China \\ * Correspondence: yzheng@whrsm.ac.cn; Tel.: +86-1347-685-6820
}

Received: 2 February 2020; Accepted: 13 March 2020; Published: 15 March 2020

\begin{abstract}
A new form of retaining system for use in deep excavations in crowded cities is proposed in this paper. The new system, which we have coined the herringbone retaining system (HRS) involves the use of vertical and batter piles, capping beams, and wales. A numerical study was conducted (using the finite difference tool FLAC3D) to investigate various aspects of the behavior of the new system and reveal the mechanisms responsible for it. The HRS method was compared subsequently to two other commonly-used systems: the cantilever retaining structure (CRS) and horizontal-strutted retaining structure (HSRS). The results show that using the HRS method significantly reduces the deformation of the vertical piles and bending moments acting on them. More specifically, the maximum values of the deformation and bending moment were calculated to be $4.5 \%$ and $23.1 \%$ of the corresponding CRS values, respectively (the corresponding figures calculated for the HSRS method are $5.3 \%$ and $19.7 \%$, respectively), so the HRS and HSRS methods provide similar levels of support. Finally, a real-world application of the system was presented to provide a valuable reference for the future use of HRS.
\end{abstract}

Keywords: deep excavation; herringbone retaining system; lateral deformation; bending moment; numerical analysis

\section{Introduction}

In metropolitan areas such as Beijing and Shanghai, booming populations and a scarcity of urban land lead to excessive congestion. To help alleviate such congestion, cities are tending to build more high-rise buildings and develop the space available underground. This, in turn, is leading to an increase in the number of deep excavation projects being undertaken (for building basements and other underground engineering structures). However, excavation induces soil movement and, sometimes, collapse of the land. This can result in adjacent buildings and utilities becoming damaged and even produce casualties [1,2]. Hence, suitable retaining structures need to be employed in these deep excavations and so engineers are facing severe challenges with respect to the design and construction of excavation support measures.

Three of the excavation methods most commonly used for deep excavation are the cantilever full open cut method, braced excavation method, and anchored excavation method [3]. Each of these methods has its own characteristics and application conditions. Cantilever retaining walls keep the excavation stable and can be embedded in the soil without the temporary installation of struts. They thus provide a large amount of room for excavation and are cheap. However, the cantilever 
full open cut method is not able to sufficiently limit the deformation that occurs when the excavation is deep.

The braced excavation method is the one most commonly used because it can limit the movement induced by the excavation process and be used in excavations of any width and at any depth [3]. However, the installation of struts may result in excavation activity being obstructed. In addition, the cost of constructing and demolishing struts is pretty high [4]. Moreover, accidents may occur, such as a strike by dropping strut and the collapse of the structure, due to strut failure $[2,5,6]$. For example, in 2010, some steel struts dropped during the excavation of Shunyi Station (part of Beijing's metro system, see Figure 1) which resulted in 2 deaths. The failure of struts also resulted in the collapse of Nicoll Highway in Singapore (see Figure 2) and 21 people died during the excavation of the Xianghu subway station (part of Hangzhou's metro system, see Figure 3) because of a collapse that occurred due to the poor state of the connection between struts and wales.

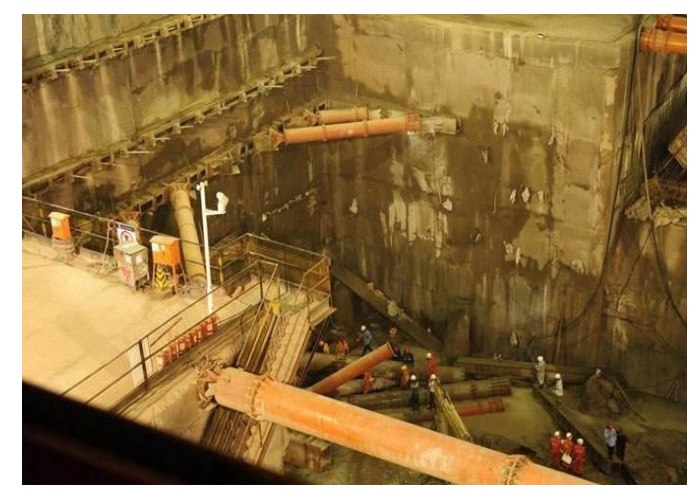

Figure 1. Strut failure of Shunyi Station in Beijing, China.

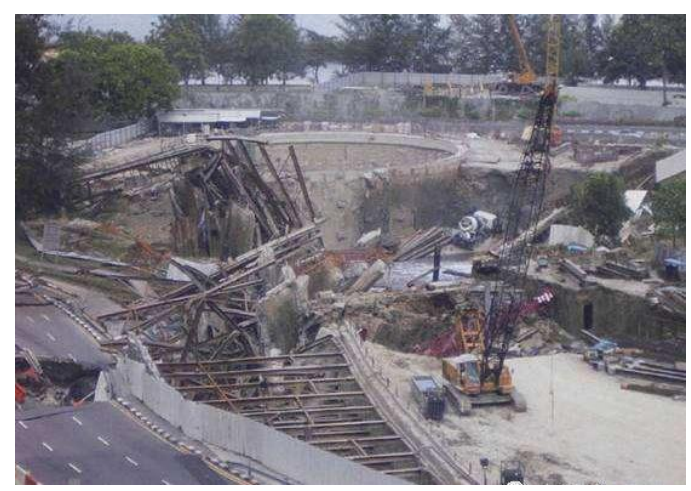

Figure 2. Nicoll Highway collapse in Singapore.

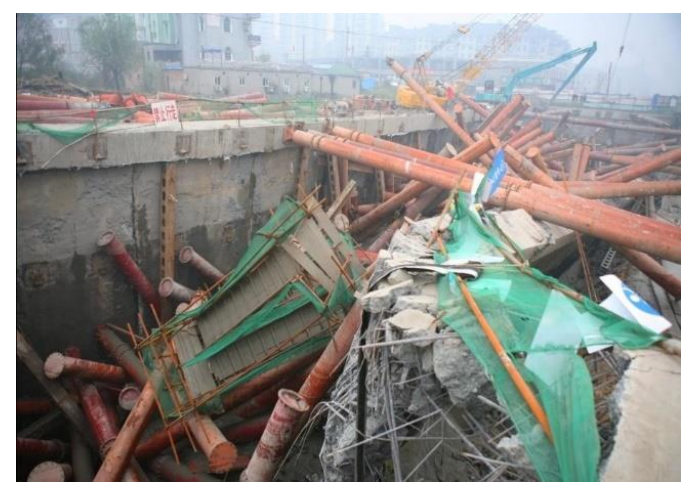

Figure 3. Collapse of Xianghu subway station in Hangzhou, China. 
Anchors can be substituted for struts to free up excavation space and improve the efficiency of the excavation and structure construction processes. However, anchors cannot work well if the soil layers are weak or lie below the groundwater table in granular soils. (An excavation collapsed in Foshan in 2015, for example, because the bearing capacity of an anchor-supported wall structure became degraded, see Figure 4. Another collapse happened in Nanning in 2019 for the same reason, see Figure 5) The use of anchors is also restricted in private areas.

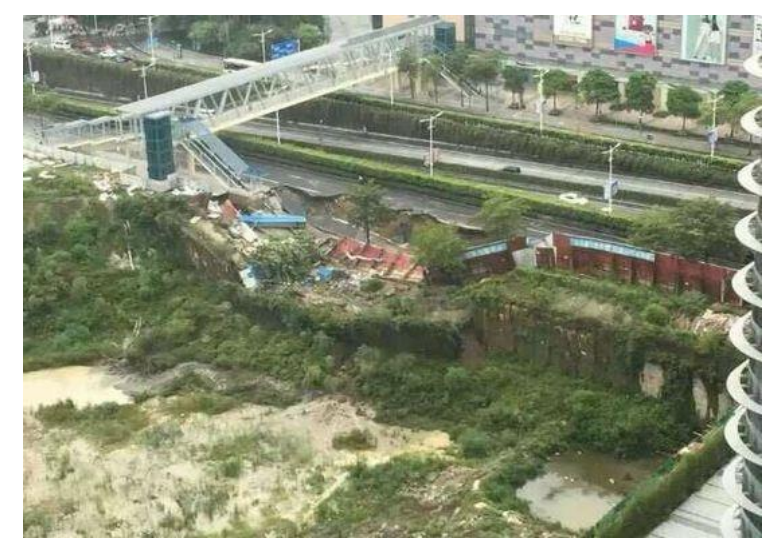

Figure 4. Collapse of an excavation in Foshan, China.

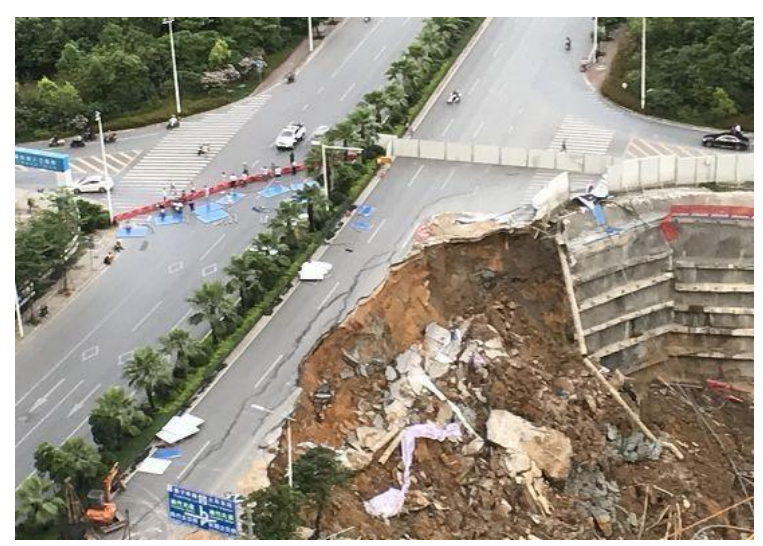

Figure 5. Collapse of an excavation in Nanning, China.

The retaining walls used in the excavation methods mentioned above can be divided into four types according to their construction characteristics, including soldier piles, steel sheet piles, column piles and diaphragm walls. Soldier piles and steel sheet piles are employed in some excavations for their fast construction with lower cost. Furthermore, the piles can be pulled out after the completion of the basement and be reusable in the following excavations. However, the two methods have their own drawbacks, such as the considerable noise caused during striking piles, low stiffness with large deformation during excavation which make them inappropriate for deep excavations [3,7].

The column pile method is to construct rows of concrete piles as retaining walls by either the cast-in situ pile method or the precast pile method. They can be designed as different patterns, such as an independent pattern, the S pattern, the line pattern, the overlapping pattern and the mixed pattern to satisfy different requirements, and the stiffness can be great with appropriate design. As a result, the column pile method is one most commonly used. The drawbacks of this method are longer construction period and higher cost than that for the two methods mentioned above.

A diaphragm wall is another method which is commonly used in deep excavations nowadays, with merits of low vibration, low noise, high rigidity and relatively small wall deformation. The thickness and depth of the walls are adjustable for different conditions. The wall can also 
be used as a permanent structure with good sealing capability. However, large items of mechanical equipment are required with long construction period and great cost.

In addition to retaining walls, strutting systems are other main components of the strutting system in a braced excavation method. There are three types of struts according to the material a strut is made of, including wood struts, reinforced concrete (RC) struts and steel struts. The wood struts can only be employed in excavations that are narrow and not deep, for their low axial stiffness. The RC struts are appropriate to excavations of various shapes with high axial stiffness. However, it takes some time for the strength of the RC strut to work and preload cannot easily act on it. Furthermore, dismantling it is difficult and costly. As for steel struts, they are widely employed for strutting systems because they are easy to install and dismantle with short construction periods and low cost, and they are easy to preload. However, they are not appropriate for excavations of great topographical undulation or of great width. Moreover, the joints of the struts are complex and highly susceptible to construction deficiency, and collapse may occur when the joints don't work (see Figures 1-3), and this issue has been discussed above.

From the discussion above, the commonly used retaining structures have their own merits and drawbacks. Because of that, new forms of retaining structure need to be designed for use in deep excavations, which can make best use of the advantages and avoid the disadvantages of the common structures. In recent years, several researchers have carried out research aimed at addressing this issue. Kim and Park, for example, introduced an innovative prestressed support system $[8,9]$ in which earth pressure is resisted using wales, wires, and H-beam support. The system provides a large amount of room for excavation activity and makes construction easy.

Cross/buttress walls have also been used to construct a new form of retaining system to protect excavations in urban areas in Taiwan [10-15]. Ou [10,11] evaluated the effectiveness of cross and buttress walls using monitoring data taken from case histories and by carrying out finite-element (FE) studies. The results thus obtained indicate that buttress walls are effective in reducing wall deflection and ground settlement. Pio-Go Hsieh [12] also studied the performance of buttress walls using FE models and found that their use can reduce the deflection of diaphragm walls moderately. Aswin Lim used an FE method to study the effect of the shape of the buttress wall on excavation-induced movement and revealed the mechanism by which the shape controls the deformation [13-15].

The aforementioned research also suggests that innovative strut designs are commonly used in engineering practice to increase stiffness, reduce the amount of space occupied, and increase the reliability of the excavation process. In this study, we introduce a new form of retaining structure for use in deep excavations. We refer to it as the 'herringbone retaining system' (HRS). The system uses batter piles to form a system of retaining struts. In this work, we investigate the effectiveness of the support system via numerical calculation and also explore the mechanisms responsible for its action.

The design scheme employed in the new system is first presented. Then, we discuss how a three-dimensional (3D) finite-difference numerical model was constructed for a notional prototype, and this was used to investigate the deformation and stress distributions in the HRS. Two further numerical models were also constructed for the same prototype that employed different retaining structures (based on cantilever and horizontal strutted systems). The three systems are then compared and used to discuss the suitability and support effectiveness of the HRS. Finally, a case study is presented to evaluate the applicability and safety of the new system.

\section{Description of the Herringbone Retaining System (HRS)}

\subsection{Structural Components}

The new retaining and protection structure is formed by installing batter piles in front of vertical piles (to give a herringbone-like structure) which helps the vertical piles resist the earth pressure acting on their backs. The full HRS consists of vertical piles, batter piles, capping beams, wales, and a curtain (for cutting off drains) — the basic configuration is shown in Figure 6. 


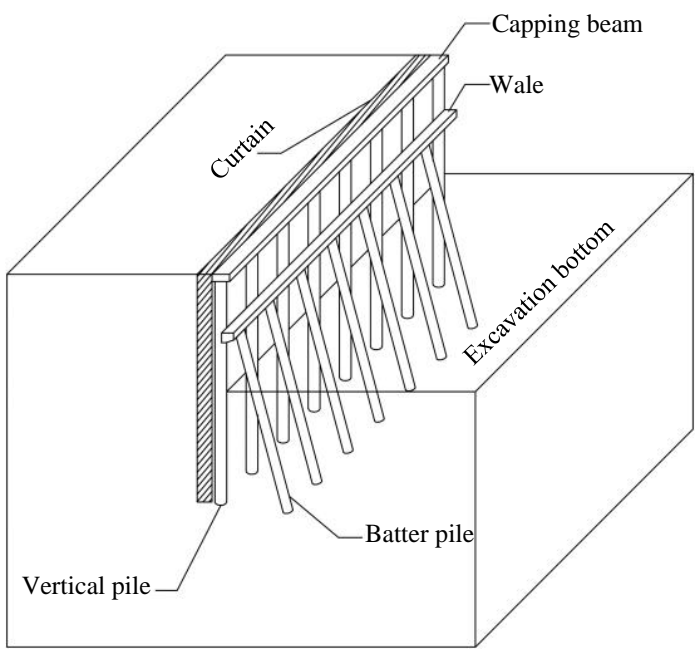

(a)

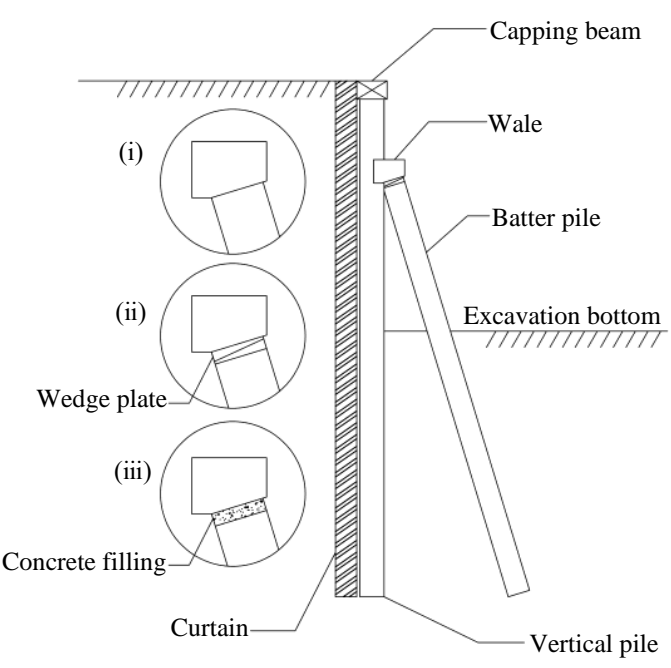

(b)

Figure 6. Basic configuration of the herringbone retaining system (HRS): (a) oblique view; (b) cross-sectional profile. (Note: (i) is the direct connection method; (ii) is the wedge plate method;

(iii) is the concrete filling method.).

Cast-in-situ bored piles are adopted for the vertical piles and they are distributed along the edge of the excavation. A capping beam, made of reinforcement concrete, is built on top of the vertical piles to make them form a unit that increases their integrity. A wale is designed as a reinforcement concrete beam or a steel beam, and it is added to the design (below the capping beam) to link the vertical piles and batter piles together. This transfers some of the load acting on the vertical piles to the batter piles. The batter piles are made of precast (PC) piles or steel piles which are paced into soil by a pre-boring method. They tilt to the inner side of the excavation and are offset with respect to the vertical piles so that they lie in between them. Clearly, their presence will act to limit the horizontal displacement of the vertical piles together with the excavation wall. There are three types of connection between the wale and batter piles: (i) direct connection method; (ii) wedge plate method; (iii) concrete filling method. That is to say, the heads of the batter piles can be supported on the wale directly if there exists no gap between them, but the wedge plate or concrete is required for filling the gap if one exists (see Figure $6 b$ ). The lower parts of the batter piles are buried in the soil below the bottom of the excavation. The curtain is a supplementary method for cutting off drains when the groundwater level is high; it is constructed by the method of high-pressure jet grouting or cement mixing piles behind the vertical piles.

\subsection{Structural Features}

Compared to conventional systems, the HRS has the following characteristics:

(1) Strong stiffness. Linking the vertical piles and batter piles to work as a whole strengthens the structural stiffness of the structure and controls the amount of excavation-induced soil movement.

(2) Highly hyperstatic and reliable. All batter piles are embedded in the soil and independent of each other, so progressive collapse will not occur if a single component fails.

(3) Its structure is compact. The batter piles do not occupy a lot of internal pit space which means that enough room is left to allow the use of large items of mechanical equipment.

(4) High efficiency and low cost. Steel-pipe batter piles can pass through the building walls or foundation slabs with limited impact on the inner structure properties [16], when they occupy the space of the inner structure with large inclination. No demolition is needed or parts of the batter piles need be demolished after completing the inner structures construction. Thus, the construction period is effectively shortened and demolition costs are reduced [4]. 


\subsection{Design Principles}

The vertical and batter piles are the two main stressed members of the HRS. The function of the vertical piles is to resist the earth pressure acting on their backs. The batter piles are built inside the excavation and are linked to the vertical piles via the wale. The lower parts of the batter piles are buried in the soil below the bottom of the excavation so that they can provide sufficient bearing capacity (frictional resistance around the surface of the pile and end-bearing resistance). The vertical and batter piles work together allowing them to control excavation-induced soil movement, thus making the excavation safe.

\section{Investigation of the Mechanisms Underlying the HRS}

\subsection{Problem Statement}

\subsubsection{Notional Prototype}

We suppose that a rectangle-shaped deep excavation is planned in sandy ground. The width of the excavation is taken to be $40 \mathrm{~m}$ while its length is much bigger than this; the excavation depth is $10 \mathrm{~m}$ (Figures 7 and 8 ). The groundwater level is assumed to be sufficiently deep that its effect on the excavation process can be ignored. The excavation is to be retained using the HRS method.

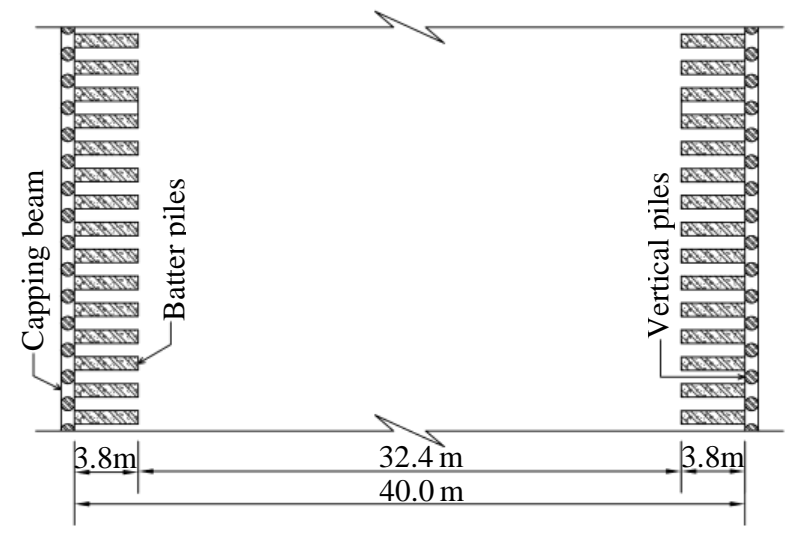

Figure 7. Plan view of the layout of the retaining system.

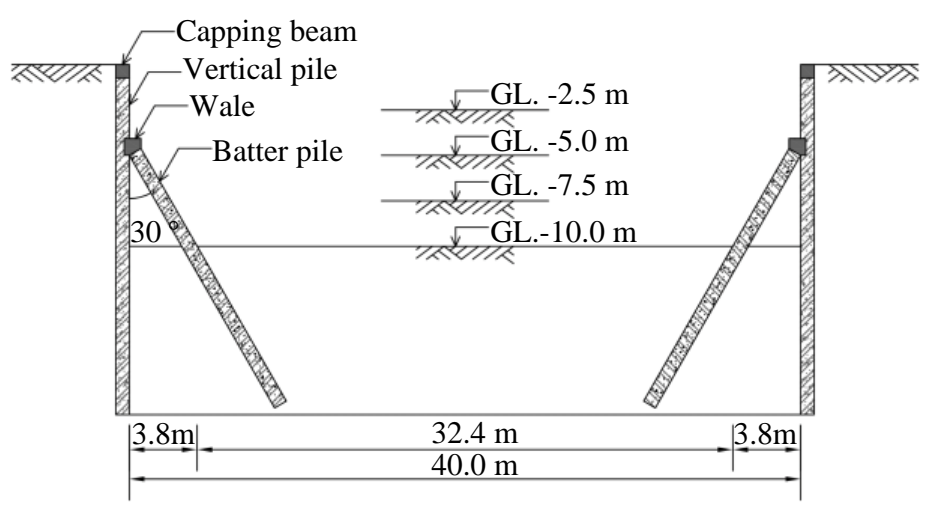

Figure 8. Profile of retaining system.

The vertical piles are taken to have diameters equal to $0.8 \mathrm{~m}$ and lengths equal to $20 \mathrm{~m}$ (the penetration depth is taken to be $10 \mathrm{~m}$ which is the same as the excavation depth). The center-center spacing of the vertical piles is $1.6 \mathrm{~m}$, i.e., twice their diameter. The capping beam is constructed on top of the vertical piles and the wale is located $5 \mathrm{~m}$ below the capping beam. The batter piles are also $0.8 \mathrm{~m}$ in diameter and are positioned so that they lie in between each pair of adjacent vertical piles. 
The batter piles are inclined and the angle they make with respect to the vertical piles is assumed to be $30^{\circ}$. The heads of the batter piles are indirectly linked to the vertical piles by the wale. The lower parts of the batter piles are buried in the soil below the bottom of the excavation. We assume that their lengths are such that their toes lie at exactly the same horizontal level as those of the vertical piles. A plan view and profile of the HRS-supported excavation are presented in Figures 7 and 8, respectively.

\subsubsection{Construction Sequence}

As HRS is a new kind of retaining structure, it is first necessary to describe the construction sequence to be used when implementing it.

The whole construction process includes construction of the vertical and batter piles, installation of the capping beam and wale, linking of the batter piles to the wale, and excavation. The vertical and batter piles are constructed before excavation. The vertical piles are designed as bored piles, and the batter piles are designed as PC piles which are placed into soil by pre-boring. The batter piles are constructed in between two adjacent piles. The capping beam is constructed after the construction of the vertical and batter piles has been completed.

Soil is then removed from ground level to a depth of $-5 \mathrm{~m}$ in two stages, followed by the installation of the wale. The batter piles are then linked to the wale. After the construction of the retaining structure has been completed, excavation is continued until the bottom is reached (i.e., in two further stages, each increasing the depth of the excavation by $2.5 \mathrm{~m}$ ). Table 1 summarizes the steps involved in the construction sequence.

Table 1. Construction sequence.

\begin{tabular}{cc}
\hline Stage & Construction Activity \\
\hline 1 & Construct the vertical piles, the batter piles and the capping beam \\
2 & Excavated to ground level $-2.5 \mathrm{~m}$ \\
3 & Excavated to ground level $-5 \mathrm{~m}$ \\
4 & Construct the wale and link them with batter piles head \\
5 & Excavated to ground level $-7.5 \mathrm{~m}$ \\
6 & Excavated to ground level $-10 \mathrm{~m}$ \\
\hline
\end{tabular}

Note: The excavation is divided into two areas in Stage 5 and Stage 6, respectively. The area in the central part of the site is excavated to a certain depth first and then the area behind the batter piles is excavated.

\subsubsection{Geological and Geotechnical Context}

This paper is mainly concerned with the effect of implementing HRS (and the mechanisms responsible for its action) when excavation is carried out in sandy soil. It is therefore assumed, for the sake of simplicity, that the soil mass consists of a single uniform layer of sand and that the groundwater level is so deep that it has no influence on the excavation process.

The deformation of the ground induced by excavation is clearly related to the deformation modulus of the soil mass around the excavation zone. Previous studies suggest that the deformation modulus depends on the confining pressure and increases linearly with the depth, $z$ [17-19]. The modulus of the soil, $E$, is therefore assumed to obey the following equation:

$$
E(z)=E_{0}+\alpha \cdot z=5+5 z
$$

where $z$ is the depth relative to the initial ground surface, $E_{0}$ is the modulus at the ground surface, and $\alpha$ is a constant of proportionality. In the second half of Equation (1), the units are such that $z$ is measured in meters and modulus in MPa. The main physical and mechanical parameters assumed in this work are presented in Table 2. 
Table 2. Summary of the main geotechnical properties of the soil stratigraphy.

\begin{tabular}{ccccccc}
\hline Soil Type & $\rho\left(\mathrm{kg} / \mathrm{m}^{\mathbf{3}}\right)$ & $c(\mathbf{k P a})$ & $\varphi\left({ }^{\circ}\right)$ & $\psi\left({ }^{\circ}\right)$ & $E(\mathbf{M P a})$ & $v$ \\
\hline Sands & 1900 & 0 & 30 & 0 & $5+5 \times z$ & 0.3 \\
\hline
\end{tabular}

Note: $\rho=$ density of soil mass; $c=$ cohesion of soil mass; $\varphi=$ internal friction angle of soil mass; $\psi=$ dilation angle of soil mass; $E=$ Young's modulus of soil mass; and $v=$ Poisson's ratio of soil mass.

\subsection{Construction of the Numerical Model}

Numerical methods are a cost-effective way of studying the behavior of retaining structures and ground movement occurring during excavation. They are also accurate because of the progress made in developing appropriate numerical codes. A large number of papers have thus verified the feasibility and accuracy of using numerical codes in the context of excavation engineering [5,10-15,17-19]. In this paper, the HRS-supported excavation process is modeled using the three-dimensional explicit finite-difference software package FLAC3D [20].

\subsubsection{Geometry and Boundary Conditions}

In light of the symmetry and geometry of the loading conditions, the center of the excavation (where the largest deformation occurs) can be assumed to meet plane strain conditions. Therefore, a quasi-3D numerical model is established for just one-half of the excavation zone to improve the efficiency of the computation process (justified on the grounds of the symmetry characteristics of the problem). The geometry of the numerical model thus constructed is shown in Figure 9.

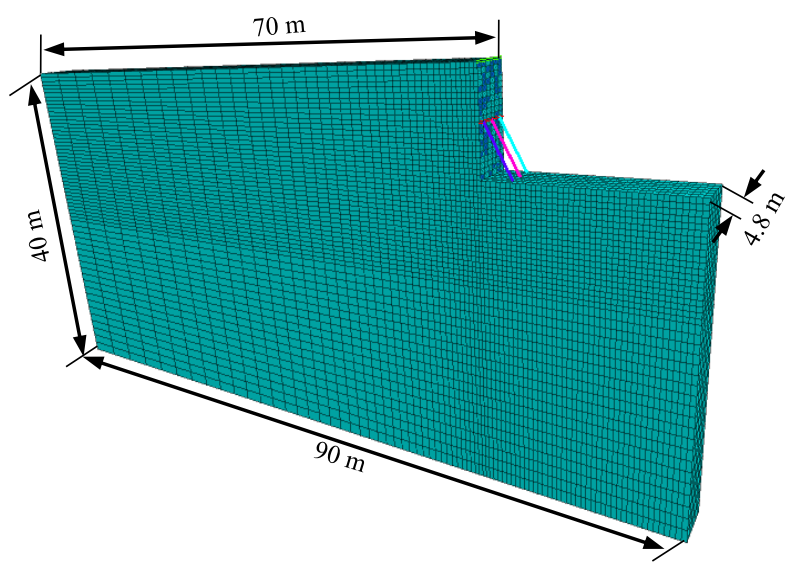

(a)

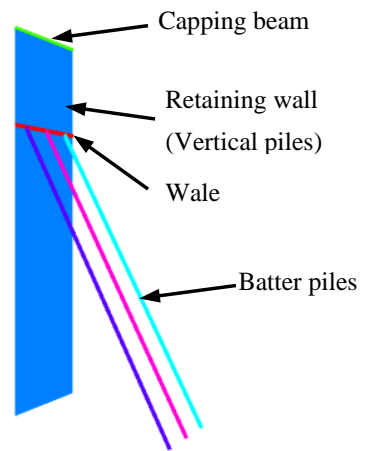

(b)

Figure 9. Three-dimensional (3D) numerical models: (a) difference element mesh of the excavation supported using the HRS method; (b) expanded view of the difference element mesh.

The overall dimensions of the model correspond to $90 \mathrm{~m} \times 40 \mathrm{~m} \times 4.8 \mathrm{~m}$. The vertical piles are positioned $70 \mathrm{~m}$ away from the left-hand boundary, i.e., 7 times the excavation depth, to reduce boundary effects [21]. The right-hand boundary corresponds to the center of the excavation zone. The thickness of the soil extends $30 \mathrm{~m}$ below the bottom of the excavation, which is regarded as fairly large. The movement of the nodes along the four lateral boundaries is constrained to be in the horizontal direction perpendicular to the side of the model. The movement of the nodes along the bottom boundary is constrained in both the vertical and horizontal directions. Figure 9 illustrates the numerical mesh used to analyze the excavation process when it is supported using the HRS method.

\subsubsection{Soil Model and Input Properties}

Previous studies $[17,21,22]$ have shown that the linear elastic-perfectly plastic Mohr-Coulomb model can be used to predict the displacement of walls induced by excavation, with only a few soil 
parameters being required. Therefore, the Mohr-Coulomb model was selected to model the behavior of the soil in this study as well. Table 2 summarizes the input parameters used to represent the soil under drained conditions. The initial stress conditions were established via gravity loading procedure. The bulk modulus, $K$, and the shear modulus, $G$, can be calculated using the formulae:

$$
\begin{aligned}
& K=\frac{E}{3(1-2 v)}, \\
& G=\frac{E}{2(1+v)},
\end{aligned}
$$

where $E$ is the modulus of the soil (calculated using Equation (1)) and $v$ is the Poisson's ratio of the soil.

\subsubsection{Structure Model and Input Properties}

Several types of structure-support members are available in FLAC3D and structures with arbitrary geometries, properties, and soil interactions can be modeled [20]. The vertical piles are essentially working as diaphragm walls that are subject to bending deformation (resulting from the active earth pressure acting behind the vertical piles, passive earth pressure in front of the vertical piles, and load from the batter piles). Therefore, the vertical piles can be converted into retaining walls of a certain thickness, $t$, based on the principle of equivalent flexural rigidity [19], and given by:

$$
t=\frac{D}{2} \sqrt[3]{\frac{3 \pi D}{2 B}}
$$

where $D$ is the diameter of a vertical pile and $B$ is the center-center spacing of the vertical piles.

Liner structural elements are attached to the surface of the grid and resist bending loading as linearly elastic shells. They can also simulate the behavior of shear-directed frictional interactions acting between themselves and the grid. Therefore, liner structural elements were used to simulate the behavior of the vertical piles after their conversion to retaining walls.

The batter piles were simulated using pile structural elements with skin-friction and end-bearing effects. The strength properties of the pile-soil interface were assumed to be equal to that of the soil mass. These assumptions have all been used in previous studies [20] and are also valid in this paper. The normal coupling spring tensile strength $\left(\sigma_{\tau}\right)$, shear coupling spring cohesion $\left(c_{s}\right)$, and shear coupling spring residual cohesion $\left(c_{r}\right)$ of the contact between the liner-grid (pile-grid) and soil around the interfaces were set to zero. The shear coupling spring friction angle $\left(\varphi_{s}\right)$ was set to be $30^{\circ}$. It is recommended by FLAC3D that the normal stiffness, $k_{n}$, and shear stiffness, $k_{s}$, were calculated using the expression [20]:

$$
k_{n}=k_{s}=10 \times \max \left[\left(K+\frac{4}{3} G\right) / \Delta z_{\min }\right],
$$

where $\Delta z_{\min }$ is the smallest dimension of a neighboring zone in the normal direction. According to Equations (1)-(3), $K$ and $G$ increase linearly with $z$. However, these parameters are assumed to be constant in this numerical analysis in order to simplify and improve the calculation efficiency. Thus, an average value was calculated $(0.46 \mathrm{GPa} / \mathrm{m})$ and used for $K$ and $G$.

The capping beam and wale components were both simulated using beam structural elements. All the structural elements were modeled using anisotropic liner elastic models. The retaining walls (vertical piles), batter piles, and beams were all taken to have a Young's modulus, $E_{s}$, of $30 \mathrm{GPa}$. Their Poisson's ratios, $v_{s}$, were taken to be 0.2 . The connections between the beams and liner elements were set to be rigid, however, the heads of the batter piles were hinged to the wale in order to prevent there being a bending moment between them. For convenience, the main properties of the structural elements used in the analysis are summarized in Table 3. The geometric parameters used for the supporting structure are consistent with those of the prototype given in Section 3.1.1. 
Table 3. Summary of the main properties of the structural elements used in the numerical analysis.

\begin{tabular}{|c|c|c|c|c|c|c|c|c|c|c|}
\hline \multirow[b]{2}{*}{ Structure Type } & \multicolumn{4}{|c|}{ Structure Properties } & \multicolumn{6}{|c|}{ Contact Properties } \\
\hline & $\begin{array}{c}\rho_{s} \\
\left(\mathrm{~kg} / \mathrm{m}^{3}\right)\end{array}$ & $\begin{array}{c}E_{S} \\
(\mathrm{GPa})\end{array}$ & $v_{\mathrm{s}}$ & $\begin{array}{c}t \\
(\mathrm{~m})\end{array}$ & $k_{n}(\mathrm{~Pa} / \mathrm{m})$ & $k_{s}(\mathrm{~Pa} / \mathrm{m})$ & $\begin{array}{c}\sigma_{\tau} \\
(\mathbf{k P a})\end{array}$ & $\begin{array}{c}c_{r} \\
(\mathbf{k P a})\end{array}$ & $\begin{array}{c}c_{s} \\
(\mathbf{k P a})\end{array}$ & $\begin{array}{l}\varphi_{s} \\
\left(^{\circ}\right)\end{array}$ \\
\hline Capping beam & 2600 & 30 & 0.2 & - & - & - & - & - & - & - \\
\hline Wale & 2600 & 30 & 0.2 & - & - & - & - & - & - & - \\
\hline $\begin{array}{c}\text { Retaining } \\
\text { walls }\end{array}$ & 2600 & 30 & 0.2 & 0.53 & $4.59 \times 10^{8}$ & $4.59 \times 10^{8}$ & 0 & 0 & 0 & 30 \\
\hline Batter piles & 2600 & 30 & 0.2 & - & $4.59 \times 10^{8}$ & $4.59 \times 10^{8}$ & 0 & 0 & 0 & 30 \\
\hline
\end{tabular}

Note: $\rho_{s}=$ density of structures; $E_{\mathrm{s}}=$ Young's modulus of structures; $v_{s}=$ Poisson's ratio of structures; $t=$ the equivalent thickness of the retaining wall; $k_{n}, k_{s}=$ normal stiffness and shear stiffness, respectively; $\sigma_{\tau}=$ normal coupling spring tensile strength; $c_{r}, c_{s}=$ residual cohesion and cohesion of shear coupling spring, respectively; $\varphi_{s}=$ shear coupling spring friction angle.

We are only interested in the forces acting on the retaining structures that arise due to excavation (rather than those induced by the installation process). Therefore, the installation of the retaining structures was modeled using a 'wished-in-place' method [23-25]. We also note that the analyses were conducted in drained conditions using effective stress and so we did not take into account the effect of the curtain.

\subsection{Results and Discussion}

\subsubsection{Behavior of the Retaining Wall (Vertical Piles)}

Figure 10 presents the results obtained for the deflection of the wall (vertical piles) at different depths after different stages of the excavation process (when the HRS is employed). The wall deflections shown are those experienced by the vertical center line of the wall (in order to reduce boundary effects). A positive value corresponds to an inward movement of the wall (piles).

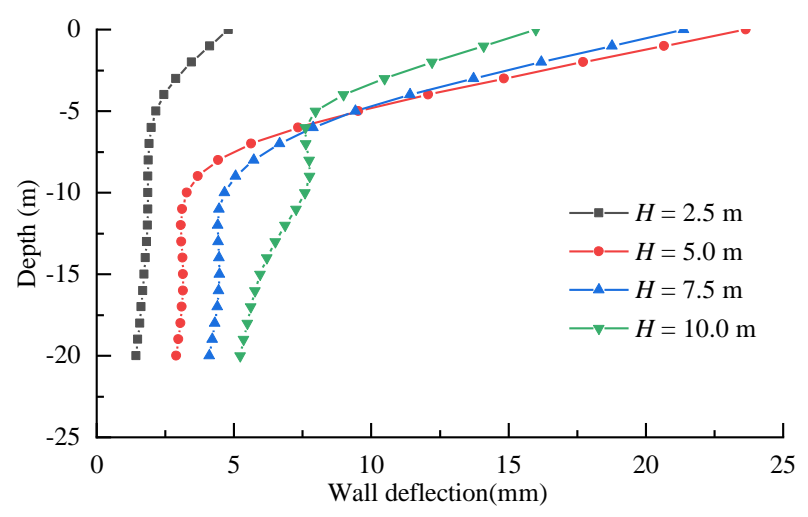

Figure 10. Variation of the horizontal deflection of the wall (vertical piles) of the HRS at different excavation depths.

As demonstrated in Figure 10, the deformation of the retaining wall (piles) gradually increased during the excavation of the 0 to $-5 \mathrm{~m}$ layer of soil. The maximum lateral deformation developed at the top of the wall (piles) and formed a triangular distribution (similar to that encountered when a cantilever retaining structure was used). During the excavation of the soil layer from -5 to $-10 \mathrm{~m}$, the top of the retaining wall (piles) rebounded outwards. At the same time, its lower parts, i.e., below the wale, continued to move inwards slightly. At the final excavation depth of $-10 \mathrm{~m}$, the deflection profile between the wale and toe of the wall (piles) is locally convex with the largest deflection occurring $1.5 \mathrm{~m}$ above the bottom. However, the maximum value of the deflection is $16 \mathrm{~mm}$ (i.e., $0.16 \%$ of $\mathrm{H}$ where $\mathrm{H}$ is the excavation depth) and still occurs at the top of the retaining wall (piles) which is 
consistent with results obtained as $\mathrm{H} \leq 5 \mathrm{~m}$. Overall, Figure 10 shows that the deflection of the retaining wall (piles) is small when it is supported by the batter piles. Furthermore, the retaining wall (piles) rotates counterclockwise around the wale, causing the top of the retaining wall (piles) to rebound outwards. This is because the batter piles act as a lateral restraint on the movement of the retaining wall (piles) at the level of the wale. The soil pressure in front of the retaining wall (piles) decreases during the excavation process, reducing the horizontal constraint on the retaining wall (piles). As a result, the deflection profile of the wall (piles) between the wale and the bottom surface bulged inwards during excavation and the top of the retaining wall (piles) rebounded outwards.

Figure 11 shows the variation of the bending moment acting on the retaining wall (piles) at the different excavation depths when it is supported using HRS. The bending moments are taken with respect to the vertical center liner of the retaining wall, a positive value corresponding to the interior cross-section of the wall being subjected to tension stress. The results depicted in Figure 11 indicate that the bending moments are negative when $\mathrm{H} \leq 5 \mathrm{~m}$ and become larger during the excavation process. The distribution of bending moments is consistent with that obtained using a cantilever retaining structure (CRS), the maximum bending moment occurring $1.5 \mathrm{~m}$ below the excavation surface.

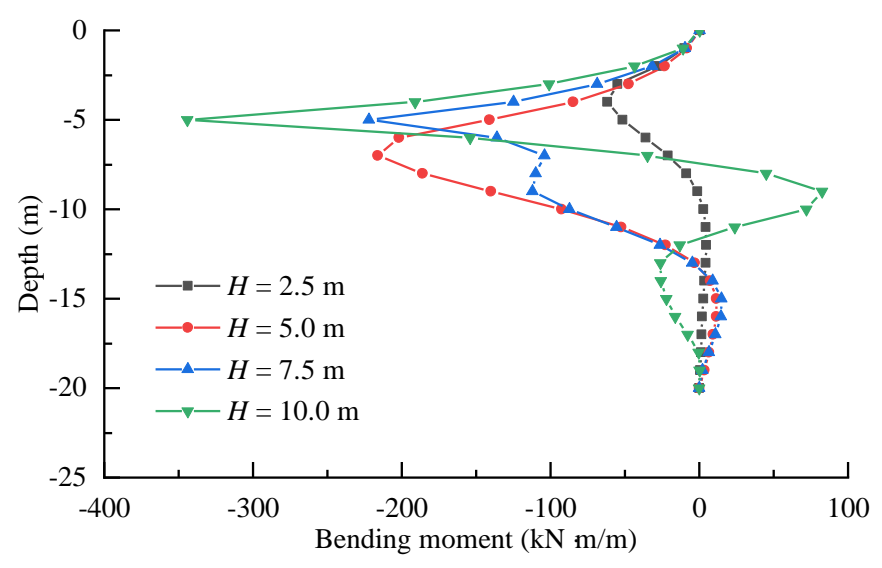

Figure 11. Variation of the bending moment acting on the wall (vertical piles) of the HRS at different excavation depths.

When $\mathrm{H}>5 \mathrm{~m}$, three obvious extrema occur in the bending moment distribution. The first extreme value occurs at the depth at which the wale is installed and its magnitude increases as excavation proceeds. This means that the earth pressure behind the portion of the retaining wall covering the 0 to $-5 \mathrm{~m}$ range increases during excavation because the top of the retaining wall (piles) rebounds outwards. The second extreme value occurs near the excavation surface. The sign of this extremum is negative when $\mathrm{H}=7.5 \mathrm{~m}$ but positive when $\mathrm{H}=10 \mathrm{~m}$. This indicates that the earth pressure in front of the retaining wall (piles) decreases as the excavation proceeds which makes the wall become locally convex.

The third set of extreme values are negative and appear below the level of the excavation surface. It can be concluded that the bending moments along the retaining wall (piles) vary in a complex manner during excavation when HRS support is employed.

\subsubsection{Behavior of the Batter Piles}

The batter piles function as a strutting system and need to provide a sufficient amount of load-bearing capacity with lateral and end-bearing resistance. Therefore, it is instructive to study the way the internal force varies inside the batter piles.

Figure 12 presents the results obtained for the axial force acting along a batter pile at different excavation depths (the results shown are those found for the middle batter pile in order to reduce any boundary effects). It can be seen that the axial force acting along the batter pile decreases gradually 
from the excavation surface down to the toe of the pile for a given excavation depth. This is consistent with the variation of the axial forces acting in piles used in building foundations. It can also be observed that the axial force increases during the excavation process. However, the slope of the curve along the batter pile decreases at the same time, indicating that the lateral resistance of the batter piles increases.

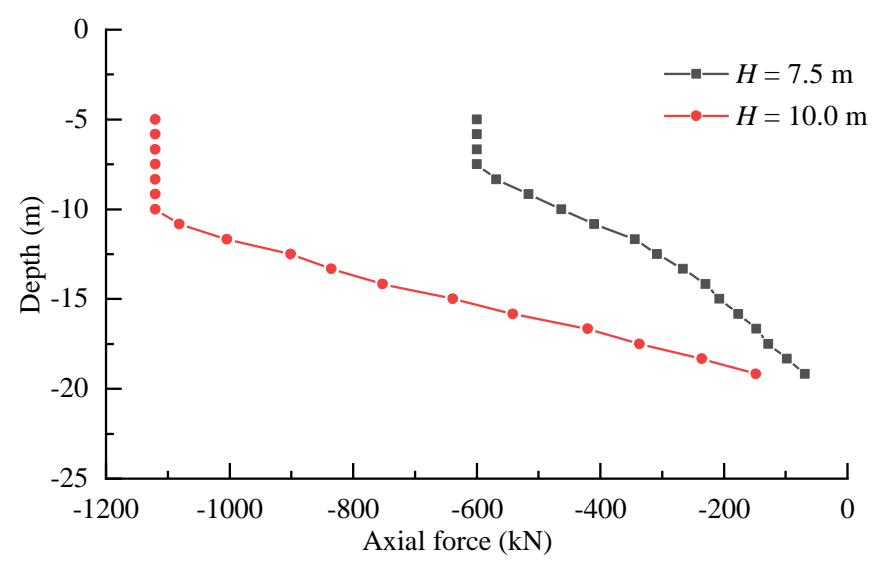

Figure 12. Variation of the axial force acting on the batter piles of the HRS at different excavation depths.

Figure 13 shows the variation of the lateral resistance along the batter pile at different excavation depths. It can be seen that the lateral resistance increases during the excavation process which is consistent with the variation in the axial force.

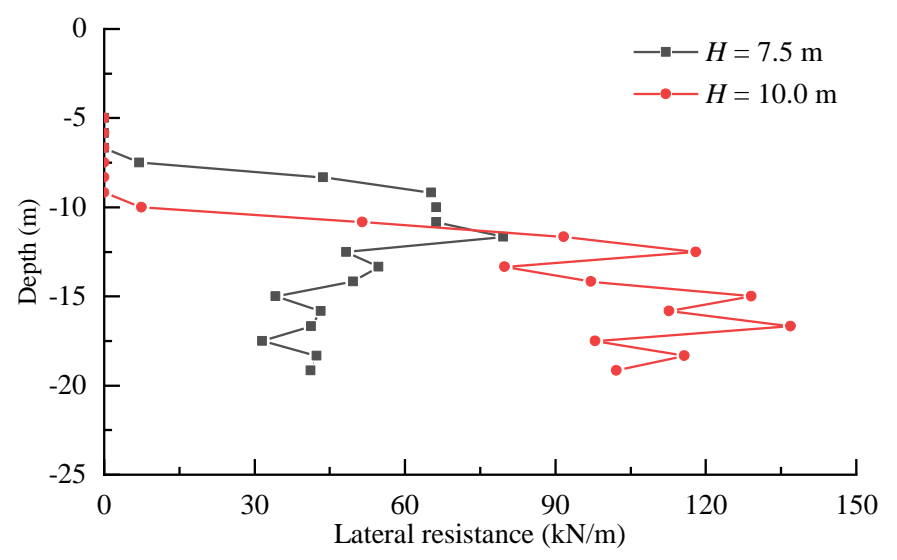

Figure 13. Variation of the lateral resistance along the batter piles of the HRS at different excavation depths.

Figure 14 shows the yield state of the shear coupling spring along the batter piles at the final excavation depth. It can be seen that there is no shear yield on the batter pile-soil interface, indicating that the mobilization of the lateral resistance of the batter piles is sufficient in this model.

Figure 15 shows the variation of the bending moments acting on the batter pile at different excavation depths (here, a positive value corresponds to when the cross-section of the batter pile towards the center of the excavation is subject to tension stress). It can be seen that the top part of the batter pile was subjected to a negative bending moment when the excavation depth was $7.5 \mathrm{~m}$, but this became positive as excavation proceeded. The bending moment developed its maximum value at a position lying below the bottom of the excavation and this position did not appear to change significantly as excavation proceeded. 


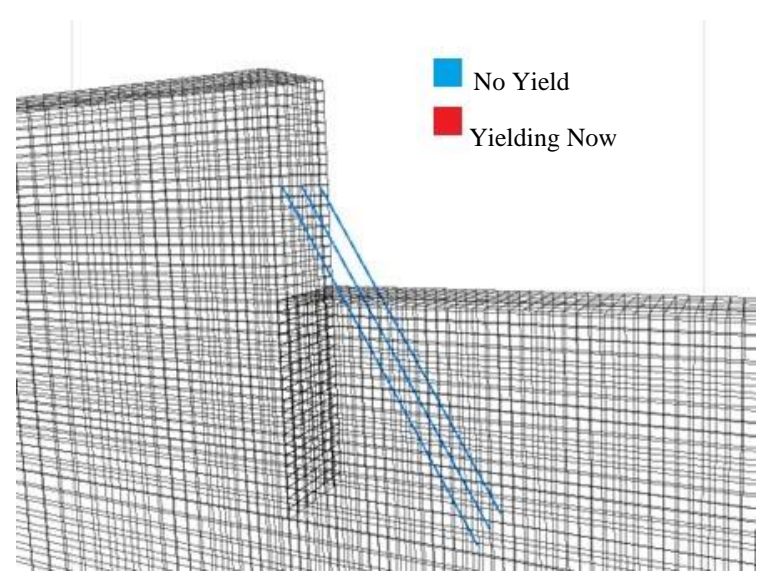

Figure 14. Yield state of the shear coupling spring along the batter piles of the HRS at the final excavation depth.

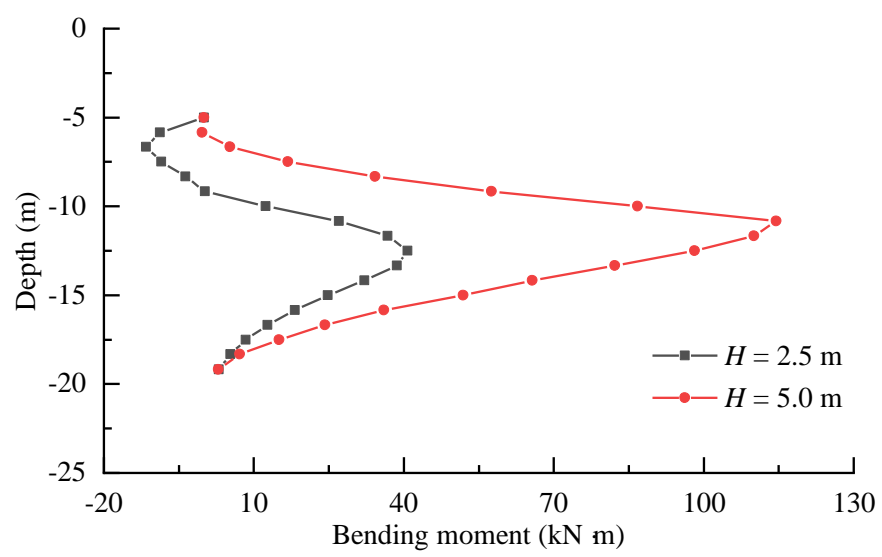

Figure 15. Variation of the bending moment acting on the batter piles of the HRS at different excavation depths.

\section{Comparison with Other Retaining Structures}

\subsection{Construction of the Additional Numerical Models}

The results presented above give us a certain understanding of the mechanism by which HRS acts during excavation. In this part, the effectiveness of HRS was compared with that of two other support measures (CRS and horizontal-strutted retaining structure (HSRS)). The comparison allows a better understanding of the effectiveness of HRS to be obtained. In order to make the comparison, two additional numerical models were constructed and analyzed.

In the CRS approach, the excavation is supported by soldier pile walls, whereas HSRS involves the use of soldier pile walls and a supplementary horizontal strutting system. The profiles of the two new excavation models were taken to be exactly the same as that given in Section 3. The parameters used for the soil and retaining structures were also taken to be unchanged (see Tables 2 and 3). The dimensions of the struts used in the HSRS approach were assumed to be the same as those used for the batter piles in the HRS approach (Figures 7 and 8), and the same applies to the other dimensions required to create the CRS and HSRS models. Numerical modeling was once again carried out using FLAC3D. Figures 16 and 17 illustrate the numerical meshes employed in the CRS and HSRS analyses, respectively. 


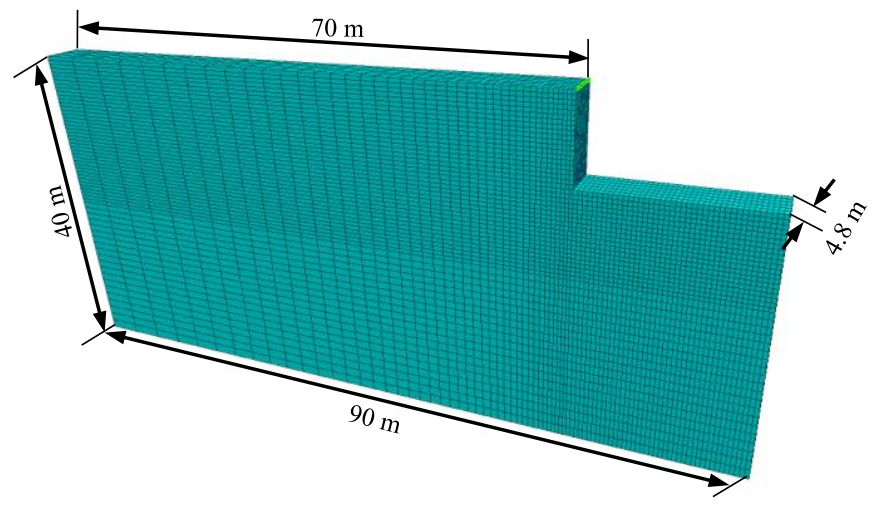

(a)

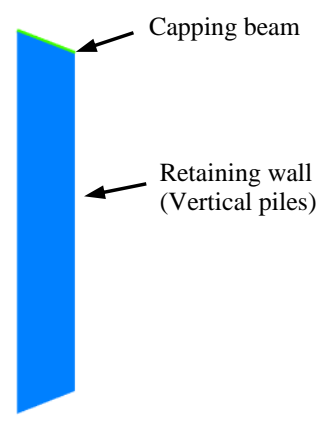

(b)

Figure 16. Three-dimensional (3D) numerical models of an excavation supported using a cantilever retaining structure (CRS): (a) difference element mesh of the excavation supported using CRS; (b) expanded view of the difference element mesh.

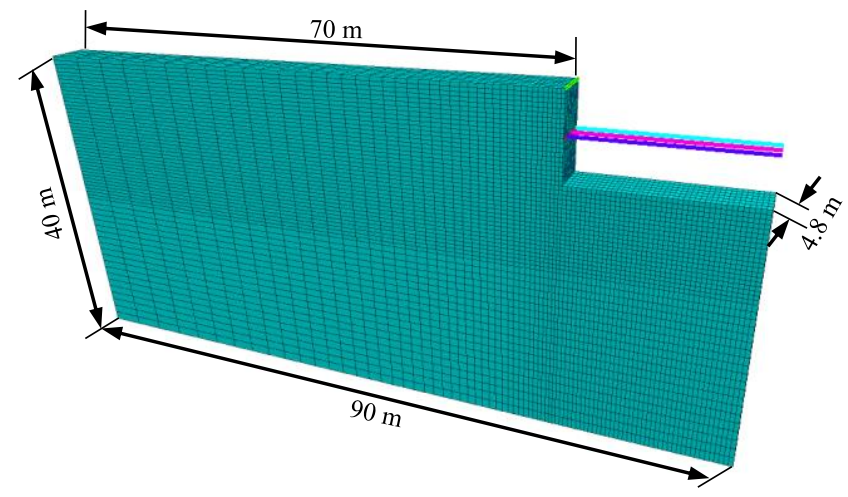

(a)

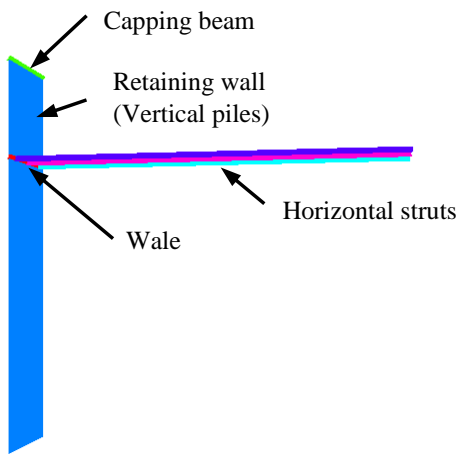

(b)

Figure 17. Three-dimensional (3D) numerical models of an excavation supported using a horizontal-strutted retaining structure (HSRS): (a) difference element mesh of the excavation supported using HSRS; (b) expanded view of the difference element mesh.

\subsection{Results and Discussion}

\subsubsection{Behavior of the Retaining Wall (Vertical Piles)}

The deflection of the wall (vertical piles) when excavation is supported using the CRS approach is presented in Figure 18. Once again, the wall deflections are taken with respect to the vertical center line of the wall and the values are taken to be positive when the wall (piles) moves inwards.

It can be seen from Figure 18 that the deformation of the wall (piles) increased significantly during the excavation process. The deflection forms a triangular distribution, with the maximum lateral wall deformation occurring at the top of the wall. The maximum movement is $26.6 \mathrm{~mm}$ when $\mathrm{H}=5 \mathrm{~m}$ and this rapidly developed to $356.9 \mathrm{~mm}$ at the final excavation depth (i.e., $3.6 \%$ of $\mathrm{H}$ with $\mathrm{H}=10 \mathrm{~m}$ ). Therefore, appropriate measures would need to be taken to control the deformation induced by the excavation process.

Figure 19 shows the evolution of the deflection of the wall (vertical piles) when HSRS-supported excavation is employed. Comparing Figure 10, Figure 18, and Figure 19, it is clear that the inclusion of batter piles or horizontal struts when $\mathrm{H}=5 \mathrm{~m}$ can effectively reduce the lateral deformation occurring during subsequent excavation. 


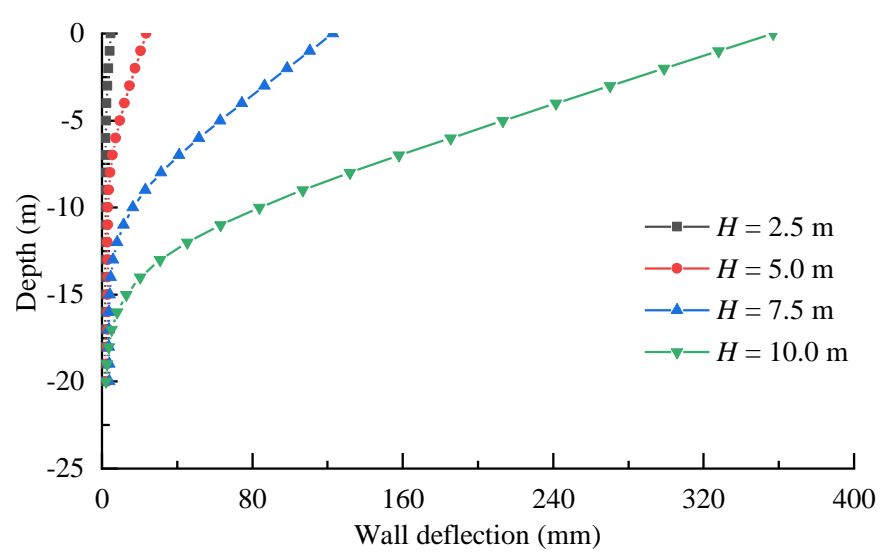

Figure 18. Variation of the horizontal deflection of the wall (vertical piles) at different excavation depths when CRS is used.

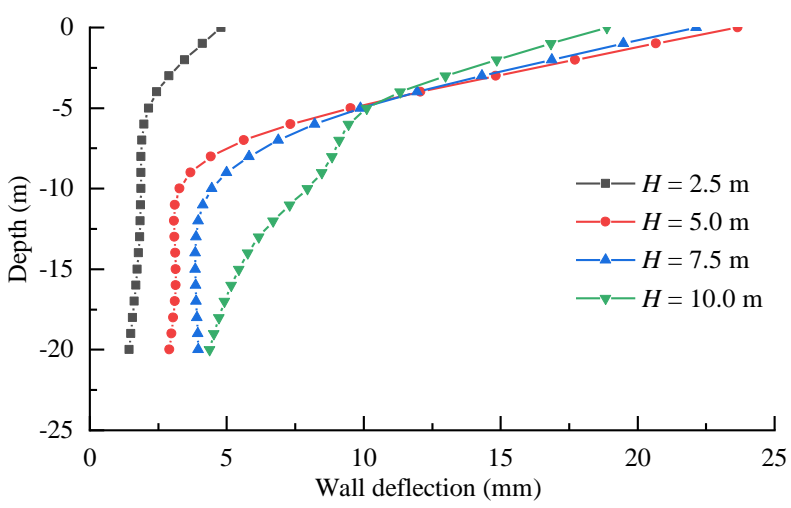

Figure 19. Variation of the horizontal deflection of the wall (vertical piles) at different excavation depths when HSRS is used.

Figure 19 shows that the maximum lateral wall movement developed at the top of the wall (piles), and that it rebounded outwards after the installation of the horizontal strut. The maximum deformations when $\mathrm{H}=10 \mathrm{~m}$ are 16.0 and $18.9 \mathrm{~mm}$ in Figures 10 and 19, respectively, which are only $4.5 \%$ and $5.3 \%$ of the corresponding CRS values shown in Figure 18. It can be seen that the maximum deformation $(16.0 \mathrm{~mm})$ when HRS is employed is a little smaller than that of the HSRS $(18.9 \mathrm{~mm})$. The reason for this phenomenon is that the lower parts of the batter piles provide resistance to the soil movements below the excavation bottom, which may reduce the wall displacement. Even so, the deflections are very similar when HRS and HSRS are employed by comparing Figures 10 and 19. This suggests that the new retaining system (HRS) is very effective at reducing lateral deformation during excavation.

Figure 20 presents the bending moments acting on the retaining wall (vertical piles) when CRS is used. (Again, the bending moments shown are those of the center liner of the retaining wall, and a positive value corresponds to the interior cross-section of the wall experiencing tension stress.) It can be seen that the bending moments are all negative and increase significantly during excavation. The maximum bending moment occurs at $1.5-3 \mathrm{~m}$ below the excavation surface. A maximum value of $-216 \mathrm{kN} \cdot \mathrm{m} / \mathrm{m}$ is obtained when the excavation depth is $5 \mathrm{~m}$, but this rapidly progresses to $-1490 \mathrm{kN} \cdot \mathrm{m} / \mathrm{m}$ by the end of the final excavation step.

Figure 21 shows the bending moments acting on the retaining wall (piles) when HSRS is used. Comparing Figures 11, 20 and 21, it is clear that installing batter piles or horizontal struts when the excavation depth is $5 \mathrm{~m}$ can significantly reduce the bending moment acting on the retaining wall (vertical piles). Three clear extreme values also appear in Figure 21 as they did in Figure 11. The first extreme values correspond to the maximum bending moments along the wall (piles) and have the 
values -344 and $-294 \mathrm{kN} \cdot \mathrm{m} / \mathrm{m}$ in Figures 11 and 21, respectively $(\mathrm{H}=10 \mathrm{~m})$. These values are only $23.1 \%$ and $19.7 \%$ of the CRS value shown in Figure 22, respectively.

Comparing Figure 11 (HRS) with Figure 21 (HSRS) shows that the two support methods generate similar bending moments in the retaining wall. Furthermore, the maximum bending moments generated using the two methods are much smaller than those generated using CRS. Therefore, our results indicate that HRS can effectively reduce the bending moment acting on the retaining wall (vertical piles) during excavation.

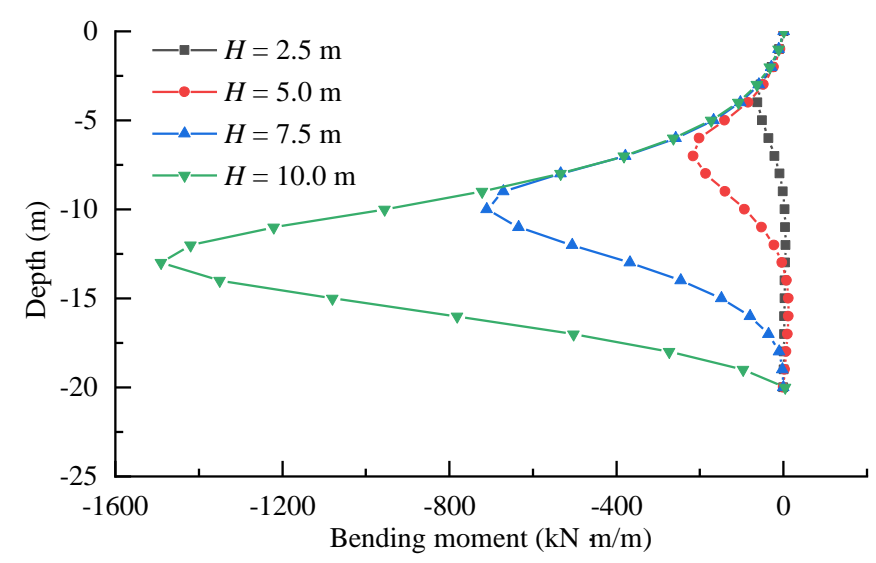

Figure 20. Variation of the bending moment acting on the wall (vertical piles) at different excavation depths when CRS is used.

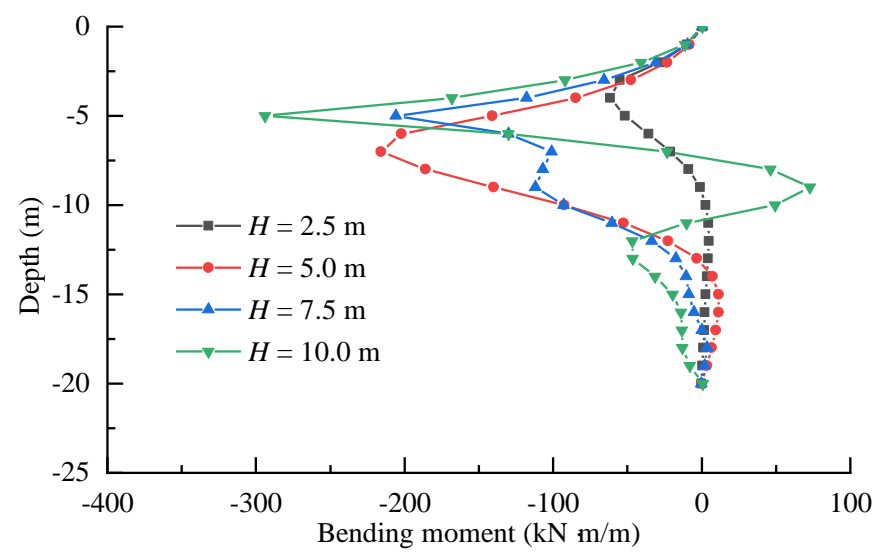

Figure 21. Variation of the bending moment acting on the wall (vertical piles) at different excavation depths when HSRS is used.

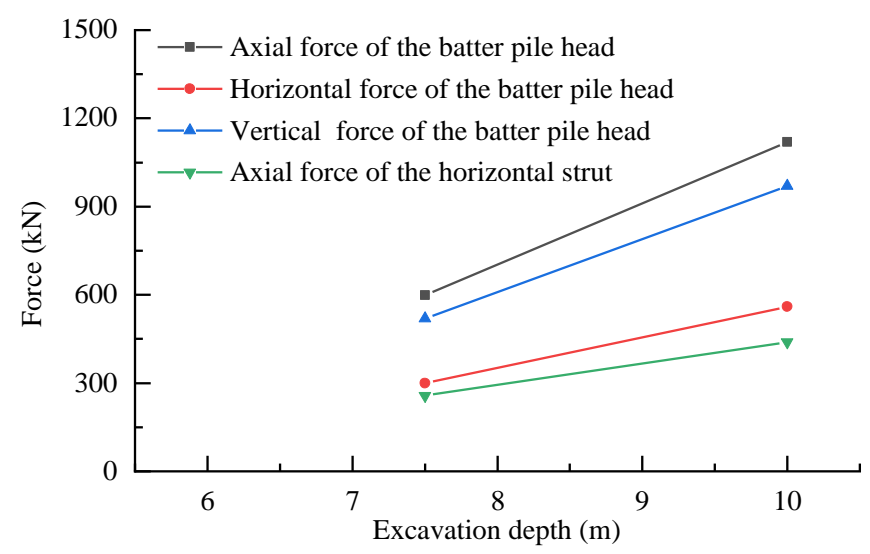

Figure 22. Load acting on the struts and batter piles at different excavation depths. 


\subsubsection{Axial Force Acting on the Struts (Batter Piles)}

Figure 22 presents the results obtained for the axial force acting on the heads of the batter piles (HRS method) and struts (HSRS method) at different excavation depths. The results are those for the middle batter pile and strut, respectively, and a positive value corresponds to the batter pile or strut being subjected to pressure.

The figure shows that the axial forces acting on both structures increase significantly during excavation. Moreover, the axial force on the batter pile head is 2.5 times that on the horizontal strut. However, the difference between the horizontal component of the force acting on the batter pile head and the axial force on the horizontal strut is small. This indicates that the batter piles need to withstand large axial loads in order to achieve the same retaining effectiveness and level of excavation protection as the horizontal struts used in the HSRS method.

\section{Case Study}

\subsection{General Project Description}

The excavation of interest is located in Wuhan, Hubei Province, China. The length of the excavation is $180 \mathrm{~m}$ and its width is $120 \mathrm{~m}$; the maximum excavation depth is $9.25 \mathrm{~m}$. According to a geological survey, the soil in the excavation area varies with depth and encompasses: miscellaneous fill, silt, clay, muddy silty clay, and clay, respectively, from the surface downwards (Table 4). The strength of the soil is low and its self-stability is poor. To facilitate construction, access roads were assigned around the excavation zone with large overloads. A main road lies adjacent to the south end of the excavation zone. As this road carries heavy traffic loads, the excavation is expected to be significantly affected by dynamic loads from vehicles. Therefore, strong retaining structures are required to protect the excavation.

Table 4. Overview of the soils encountered in the scope of the excavation.

\begin{tabular}{ccccc}
\hline Soil Layers & Depth $(\mathbf{m})$ & $c(\mathbf{k P a})$ & $\boldsymbol{\varphi}\left({ }^{\circ}\right)$ & $\boldsymbol{E}_{\mathbf{s}(\mathbf{1 - 2})}(\mathbf{M P a})$ \\
\hline Miscellaneous fill & $1.0-4.8$ & 10.0 & 8.0 & - \\
Silt & $0.4-2.5$ & 8.0 & 3.0 & 2.0 \\
Clay & $0.5-4.4$ & 22.0 & 11.0 & 5.5 \\
Muddy silty clay & $2.2-8.7$ & 9.0 & 3.5 & 2.5 \\
Clay & $1.7-11.0$ & 30.0 & 14.0 & 8.0 \\
Clay & $1.4-4.0$ & 20.0 & 10.0 & 5.0 \\
\hline
\end{tabular}

\subsection{Description of the Retaining System}

A retaining system based on the new HRS method was designed to protect the excavation based on the environmental and geological conditions of the site described above (see Figures 23 and 24). The design involved first excavating the soil to a depth of $3.25 \mathrm{~m}$ with slope of $40^{\circ}$. Then, the next $6 \mathrm{~m}$ of the excavation process (from -3.25 to $-9.25 \mathrm{~m}$ ) was to be protected using the HRS approach. The main supports were to be based on bored cast-in-situ vertical piles $(\Phi 800 \mathrm{~mm})$ and steel pipe batter piles $(\Phi 500 \mathrm{~mm})$. The vertical piles were to have a center-center spacing of $1.5 \mathrm{~m}$. The batter piles were placed into soil by pre-boring with an inclination of $17^{\circ}$. The pre-boring holes for steel pipe batter piles were drilled by an improved machine, which is modified from the machine used to drill holes for anchors (see Figure 25). The drill bit diameter of the machine is $500 \mathrm{~mm}$, and it can drill a hole in ground with an inclination of $0-45^{\circ}$ from a vertical axis. It is the first application of the new machine in this case. The steel pipe piles were filled with cement mortar after they were placed into the ground, in order to increase batter pile stiffness. The gap between the wale and the batter pile head was filled with concrete. An anchor cable inclined at $35^{\circ}$ from a horizontal axis was also incorporated into the design (at the top of the bored piles) to further strengthen the retaining system. High-pressure rotary 
sprayed piles measuring $\$ 800 @ 500 \mathrm{~mm}$ were also constructed to act as a waterproof curtain behind the cast-in-situ piles.

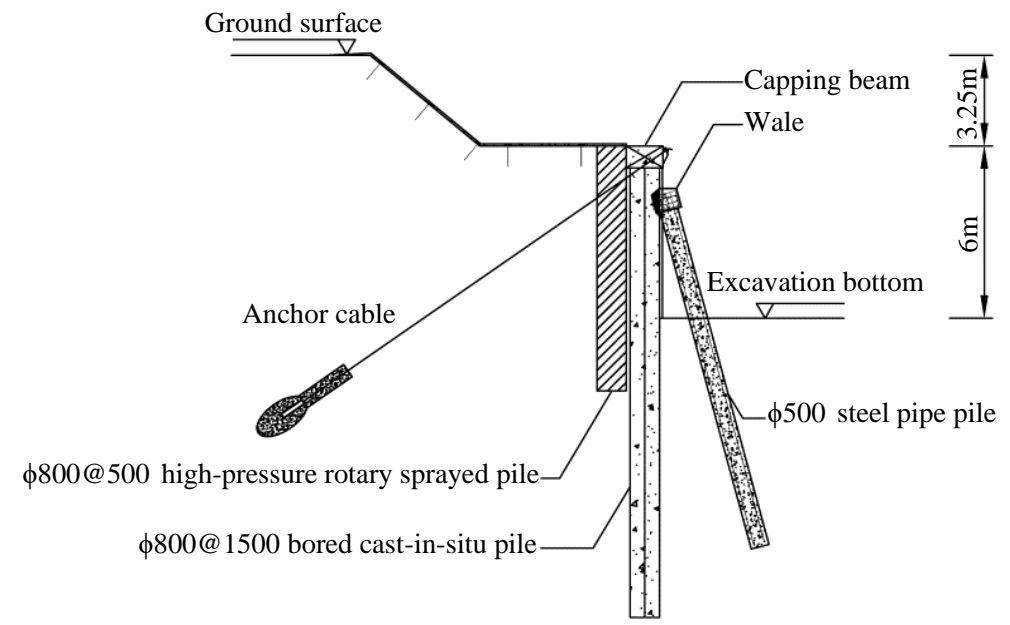

Figure 23. Schematic profile of the excavation support system.

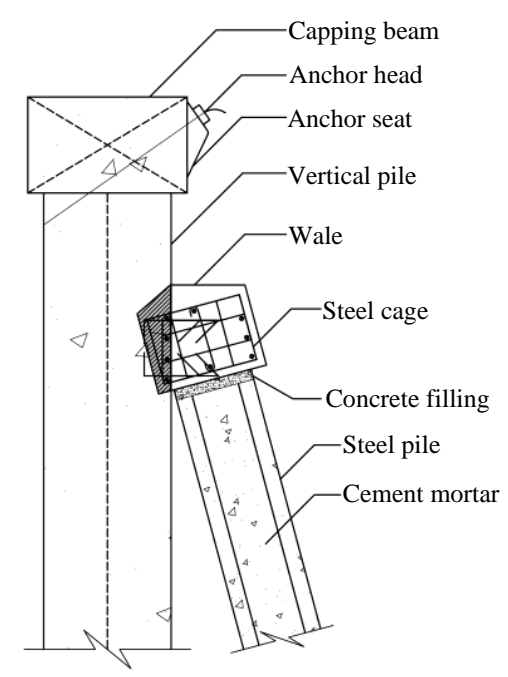

Figure 24. Details of the construction of the joint between the wale and the piles.

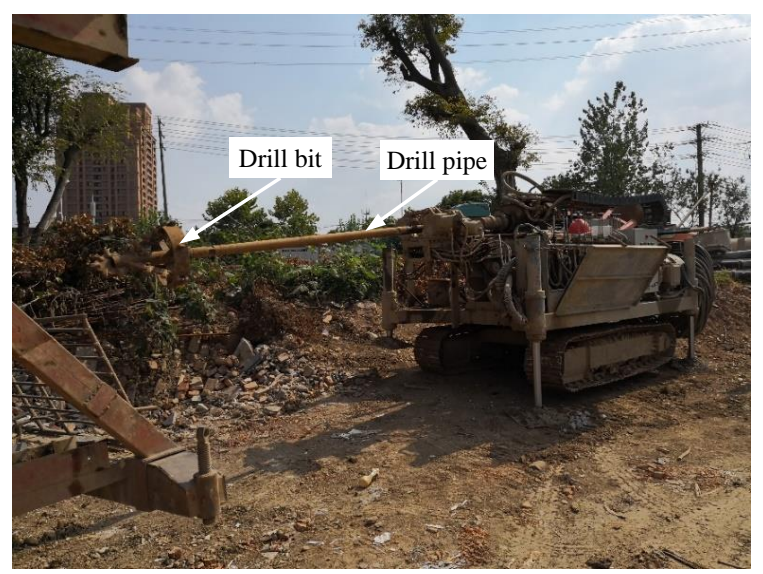

Figure 25. Photograph of the drilling machine used to drill holes for batter piles. 


\subsection{Support Effect}

Unfortunately, no monitoring data are available to allow the effectiveness of the retaining system to be determined. However, HRS was successfully implemented at the site, as witnessed by the photographs presented in Figure 26. It is notable that no significant deformation or collapse of the excavation occurred during the construction process. Thus, the internal structure was completed successfully and the excavation backfilled as required. Furthermore, the batter piles only occupied a small amount of space inside the excavation and had no influence on the construction of the earthwork and internal structure. As a result, the batter piles did not need to be dismantled, reducing the cost of the construction process and improving its efficiency. In addition, the new drilling machine was first applied in practice, which provided experience for studying the construction technology. Therefore, even though the details of the excavation process are somewhat incomplete, the excavation carried out in Wuhan can be seen as a valuable test case for the application of the new HRS method.

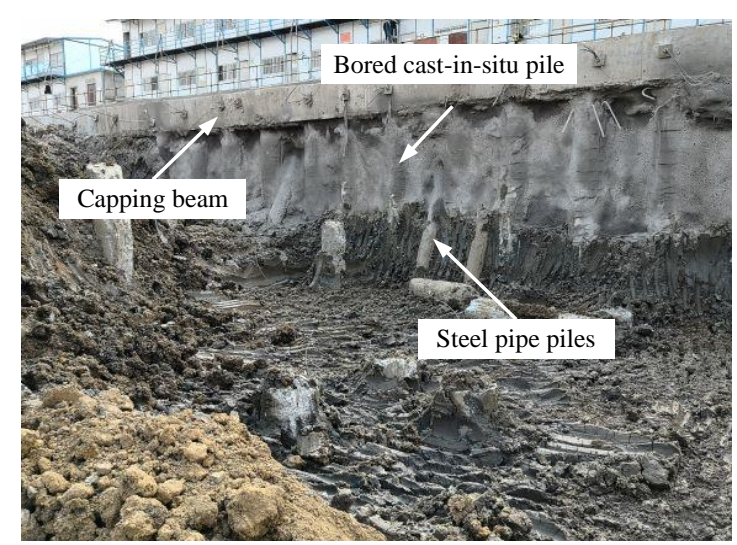

(a)

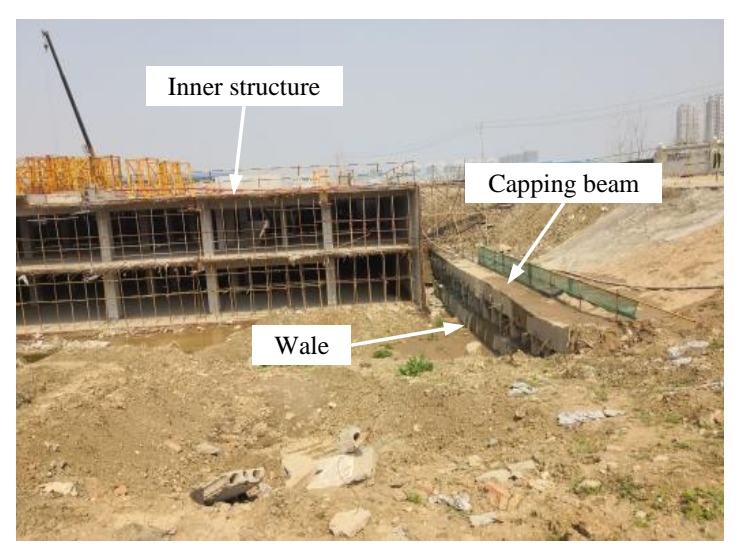

(b)

Figure 26. Photographs of the excavation and strutting system showing: (a) the west side of the excavation; (b) the east side of the excavation.

\section{Conclusions}

A new retaining system named HRS was introduced. Three numerical models were constructed and analyzed to study the action mechanism and effectiveness of the new retaining system in reducing lateral pile deflection and bending moment. The following conclusions can be drawn from the analyses presented in this paper:

(1) When HRS is used, the vertical piles rotate around the wale during excavation. This causes the tops of the vertical piles to rebound outwards while their lower parts (between the wale and their toes) move slightly inwards because of the restraining effect of the batter piles.

(2) During HRS-supported excavation, the bending moments acting on the vertical piles vary in a complex manner along the length of the piles. Three obvious extreme values may develop and the largest bending moment develops at the point where the wale is installed.

(3) During HRS-supported excavation, the axial and lateral resistance forces acting on the batter piles increase as excavation proceeds and provide adequate support for the vertical piles. The batter piles are subjected to a certain bending moment and the position at which the maximum bending moment occurs does not change significantly as excavation proceeds.

(4) Our results show that HRS is a viable alternative measure to use to protect excavations. The lateral deformation of the vertical piles and bending moments acting on them are significantly reduced compared to the CRS method. The level of support is as good as that provided using the HSRS method. 
It should be mentioned that the study in this paper is based on an excavation with idealized conditions. Certain parameters, including soil conditions, geometric configurations of the HRS, the stiffness of the retaining walls, and strutting systems are not taken into consideration. Thus, readers should be cautious of any extrapolation from the results above. Further investigations are needed to study the mechanism and the construction technology of the HRS through numerical methods, a physical model experiment, and field tests in the future.

Author Contributions: Conceptualization and methodology, C.C. and M.L.; Data curation, H.Z.; Software, Y.S.; Writing — original draft, Y.Z. (Yapeng Zhang); Writing—review and editing, Y.Z. (Yun Zheng). All authors have read and agreed to the published version of the manuscript.

Funding: The research was funded by National Key R\&D Program of China (Grant No. 2017YFC0805307) and Natural Science Foundation of Hubei province, China (Grant No. 2018CFB450).

Conflicts of Interest: The authors declare no conflict of interest. The funders had no role in the design of the study; in the collection, analyses, or interpretation of data; in the writing of the manuscript; or in the decision to publish the results.

\section{References}

1. Xu, L.; Xu, Y.; Wang, C.; Feng, K. Data-driven deformation reliability of retaining structures in deep excavations considering measurement error. Appl. Sci. 2019, 9, 5466. [CrossRef]

2. Goh, A.T.C.; Fan, Z.; Hanlong, L.; Wengang, Z.; Dong, Z. Numerical Analysis on Strut Responses Due to One-Strut Failure for Braced Excavation in Clays. Springer Ser. Geomech. Geoengin. 2018, 2, 560-574. [CrossRef]

3. Ou, C.Y. Deep Excavation: Theory and Practice; Taylor and Francis: London, UK, 2006.

4. Nie, D.Q. Study on the interaction mechanism and stability of multi-bench retaining structures of excavations. Ph.D. Thesis, Tianjin University, Tianjin, China, 2017.

5. Zhang, W.; Zhang, R.; Fu, Y.; Goh, A.T.C.; Zhang, F. 2D and 3D numerical analysis on strut responses due to one-strut failure. Geomech. Eng. 2018, 15, 965-972. [CrossRef]

6. Endicott, J. Lessons learned from the collapse of the Nicoll Highway in Singapore April 2004; IABSE Symposium Report; International Association for Bridge and Structural Engineering: Zurich, Switzerland, 2013; Volume 101, pp. 1-6. [CrossRef]

7. Robert, W.D. Foundation Engineering Handbook: Design and Construction with the 2006 International Building Code, 1st ed.; McGraw-Hill Company: New York, NY, USA, 2006.

8. Kim, N.K.; Park, J.S.; Han, M.Y.; Kim, M.Y.; Kim, S.B. Development of Innovative Prestressed Support Earth Retention System. J. Korean Geotech. Soc. 2004, 20, 107-113.

9. Park, J.S.; Kim, N.K.; Han, M.Y.; Kim, J.W. A new IPS earth retention system. Proceedings of The 16th International Conference on Soil Mechanics and Geotechnical Engineering, Osaka, Japan, 12-16 September 2005; IOS Press: Amsterdam, The Netherlands, 2005; pp. 1369-1372. [CrossRef]

10. Ou, C.Y.; Teng, F.C.; Seed, R.B.; Wang, I.W. Using buttress walls to reduce excavation-induced movements. Proc. Inst. Civ. Eng. Geotech. Eng. 2008, 161, 209-222. [CrossRef]

11. Ou, C.Y.; Hsieh, P.G.; Lin, Y.L. Performance of excavations with cross walls. J. Geotech. Geoenvironmental Eng. 2010, 137, 94-104. [CrossRef]

12. Hsieh, P.G.; Ou, C.Y.; Lin, Y.K.; Lu, F.C. Lessons learned in design of an excavation with the installation of buttress walls. J. Geoengin. 2015, 10, 63-73. [CrossRef]

13. Lim, A.; Hsieh, P.G.; Ou, C.Y. Evaluation of buttress wall shapes to limit movements induced by deep excavation. Comput. Geotech. 2016, 78, 155-170. [CrossRef]

14. Lim, A.; Ou, C.Y.; Hsieh, P.G. Investigation of the integrated retaining system to limit deformations induced by deep excavation. Acta Geotech. 2018, 13, 973-995. [CrossRef]

15. Lim, A.; Ou, C.Y.; Hsieh, P.G. An innovative earth retaining supported system for deep excavation. Comput. Geotech. 2019, 114, 103135. [CrossRef]

16. Romashko, O.; Romashko, V. Evaluation of bond between reinforcement and concrete. MATEC Web Conf. 2018, 230, 1-7. [CrossRef]

17. Houhou, M.N.; Emeriault, F.; Belounar, A. Three-dimensional numerical back-analysis of a monitored deep excavation retained by strutted diaphragm walls. Tunn. Undergr. Sp. Technol. 2019, 83, 153-164. [CrossRef] 
18. Houhou, M.N.; Emeriault, F.; Vanoudheusden, É. Three-Dimensional Back-Analysis of an Instrumented Shallow Tunnel Excavated by a Conventional Method. Geotech. Geol. Eng. 2016, 34, 1101-1117. [CrossRef]

19. Li, A.Z.; Lehane, B.M. Embedded cantilever retaining walls in sand. Geotechnique 2010, 60, 813-823. [CrossRef]

20. Itasca Consulting Group. Fast Lagrangian Analysis of Continua in 3 dimensions, interfaces. In User Manual of FLAC3D 5.0; Itasca Consulting Group: Minneapolis, MN, USA, 2012.

21. Hsiung, B.C.B.; Yang, K.H.; Aila, W.; Hung, C. Three-dimensional effects of a deep excavation on wall deflections in loose to medium dense sands. Comput. Geotech. 2016, 80, 138-151. [CrossRef]

22. Khoiri, M.; Ou, C.Y. Evaluation of deformation parameter for deep excavation in sand through case histories. Comput. Geotech. 2013, 47,57-67. [CrossRef]

23. Dong, Y.P.; Burd, H.J.; Houlsby, G.T. Finite-element analysis of a deep excavation case history. Geotechnique 2016, 66, 1-15. [CrossRef]

24. Hsiung, B.C.B. A case study on the behaviour of a deep excavation in sand. Comput. Geotech. 2009, 36, 665-675. [CrossRef]

25. Zheng, G.; Yang, X.; Zhou, H.; Du, Y.; Sun, J.; Yu, X. A simplified prediction method for evaluating tunnel displacement induced by laterally adjacent excavations. Comput. Geotech. 2018, 95, 119-128. [CrossRef]

(C) 2020 by the authors. Licensee MDPI, Basel, Switzerland. This article is an open access article distributed under the terms and conditions of the Creative Commons Attribution (CC BY) license (http://creativecommons.org/licenses/by/4.0/). 